\title{
Hypothalamic hamartomas with gelastic seizures
}

INSERM

\section{Source}

INSERM. (1999). Orphanet: an online rare disease and orphan drug data base. Hypothalamic hamartomas with gelastic seizures. ORPHA:86906

Hypothalamic hamartomas with gelastic seizures is a rare cerebral malformation with epilepsy syndrome characterized by early-onset gelastic (i.e. ictal laughter) or dacrystic (i.e., ictal crying) seizures due to non-neoplastic developmental malformation hypothalamic hamartomas. In many patients, seizures progress to other seizure types including focal and generalized seizures, with concomitant cognitive decline and behavioral disorders. Some patients also present a precocious puberty. 